\title{
La alusión como mecanismo cognoscitivo
}

\author{
Allusion as a cognitive mechanism \\ Pedro J. Chamizo Domínguez \\ Universidad de Málaga (España)
}

Recibido: 12.05 .2020

Aceptado: 06.04.2021

\section{RESUMEN}

A pesar de que la alusión es ampliamente usada por poetas, escritores y filósofos así como en el lenguaje cotidiano, sus características y alcance como instrumento cognitivo se han estudiado escasamente. Esto es cierto hasta el extremo de que el sustantivo alusión no es merecedor de una humilde entrada en diccionarios y enciclopedias especializados, no solamente de filosofía, sino tampoco de lingüística. Teniendo en cuenta este status quaestionis, este trabajo intenta conseguir los siguientes objetivos, a saber: 1) mostrar que la alusión es un instrumento cognitivo; 2) delimitar la alusión con respecto a la cita, el plagio y el eco; 3) considerar la alusión como un caso de implicatura; y 4) analizar las principales características de la alusión. Todos estos puntos se estudian mediante el recurso a textos poéticos y filosóficos serios, así como a textos y proferencias humorísticos y del lenguaje cotidiano.

PALABRAS CLAVE

ALUSIÓN, CITA, PLAGIO, ECO, MÁXIMAS CONVERSACIONALES, IMPLICATURA.

\begin{abstract}
In spite of the fact that allusion is widely used by poets, writers and philosophers as well as in everyday language, its features and scope as a cognitive device have been scarcely studied. This is true to the de extent that the noun allusion is not worth a humble entry in specialized dictionaries and encyclopaedias, not only of philosophy, but also neither of linguistics. Taking into account such a status quaestionis, this paper attempts to achieve several goals, namely, 1) showing that allusion is a cognitive device; 2) defining allusion with regard to quotation, plagiarism and echo; 3) considering allusion as a case of implicature; and 4) analysing the main features of allusion. All these items are studied by means of appealing to serious, poetic and philosophical texts as well as humorous and everyday language texts and utterances.
\end{abstract}

Claridades. Revista de filosofía 13/2 (2021), pp. 85-118.

ISSN: 1889-6855 ISSN-e: 1989-3787 DL.: PM 1131-2009

Asociación para la promoción de la Filosofía y la Cultura en Málaga (FICUM) 


\section{KEY WORDS \\ ALLUSION, QUOTATION, PLAGIARISM, ECHO, CONVERSATIONAL MAXIMS, IMPLICATURE.}

\section{O. INTRODUCCIÓN}

En su influyente y seminal artículo sobre la metáfora, se quejaba M. Black de que los filósofos, "for all their notorious interest in language» (Black, 1954-1955: 273), hubiesen ninguneado este tema, porque «if philosophers have something more important to do than give pleasure to their readers, metaphor can have no serious place in philosophical discussion» (Black, 1954-1955: 282). A pesar de ello, lo mismo los filósofos contemporáneos de Black que los anteriores habían recurrido al uso de metáforas, e, incluso, muchos de ellos las habían creado ellos mismos, lo cual, según Aristóteles,

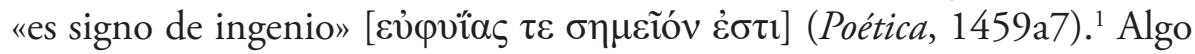
análogo a lo que pasaba en los años 50 del siglo pasado con respecto a la metáfora acontece todavía hoy con respecto a la alusión. A pesar de que la alusión es un recurso abundantemente usado por los filósofos de cualquier escuela o tendencia, hasta dónde he podido indagar no he encontrado, ni en la tradición filosófica ni en la actualidad, reflexiones sobre este fenómeno, que puede convertirse en piedra angular a la hora de interpretar un texto, no solamente literario, sino también filosófico.

De hecho, aunque el sustantivo alusión es usado muy frecuentemente, sin embargo, no es merecedor de una entrada específica en prestigiosos diccionarios de filosofía de uso habitual entre los estudiantes y profesionales de la filosofía. Para no alargar el listado más de lo necesario, haré referencia aquí solamente a algunos diccionarios filosóficos de reconocido prestigio publicados en el siglo XX en las lenguas de mayor número de hablantes de la Europa occidental y en los que se usa el sustantivo alusión, pero que no es definido en ningún momento. Efectivamente, aunque en ellos se suele usar el sustantivo, ninguno de ellos considera el tema con la suficiente enjundia filosófica como para dedicarle una entrada. Así sucede, por ejemplo, con

1 Estas palabras se han traducido también como «it is also a sign of genius» (Aristotle, 1959: 349), como «es indicio de talento» (Aristóteles, 1974: 214), como «è segno di una naturale disposizione di ingegno" (Aristotele, 1992: 1047) y como «è segno di buona natura» (Aristotele, 2004: 643). 
los diccionarios de Abbagnano (1971), Audi (1999), Baldwin (1901), Eisler (1910), Ferrater Mora (2004) o Lalande (1976).

Dado que en los diccionarios generales de filosofía parece no tener cabida la conceptualización de qué sea una alusión, pudiera pensarse que, dado que se puede considerar como mínimo un tema digno de reflexión por parte de la filosofía del lenguaje, en especial de la pragmática del lenguaje, las enciclopedias de filosofía en general y de pragmática del lenguaje en particular bien hubieran podido dedicarle una entrada. Pero tampoco acontece esto, por citar solamente obras recientes y amplias, ni en los diez tomos de la Encyclopedia of Philosophy (Borchert, 2006), ni en los 12 tomos de la Encyclopedia of Language and Linguistics (Brown, 2006). Ni tampoco en diccionarios o enciclopedias de filosofía del lenguaje o pragmática del lenguaje tales como Tanesini (2007), Lamarque (1997) o Mey (2009), a pesar de que la interpretación de una alusión es un asunto de relevancia cognitiva y fundamentalmente pragmático. Para encontrar obras en las que se dedique una entrada específica a la alusión hay que recurrir a obras sobre términos literarios o retóricos como Baldick (2001), aunque el análisis que se hace de la alusión está conectado con textos literarios sin que se haga ninguna referencia a los aspectos cognitivos de ese fenómeno. Pero, dado que, ni los diccionarios generales de filosofía ni los más especializados de filosofía del lenguaje o lingüística, proporcionan ninguna definición de alusión. Quizás la responsabilidad de este olvido haya que atribuirla al anatema decretado por filósofos como J. Locke, para quien la metáfora, el lenguaje figurado y la alusión obran justamente de modo contrario a como lo hace el juicio para «to avoid being misled by similitude, and by affinity to take one thing for another» (Locke, 1908: I, 272), en la medida en que "wit and fancy find easier entertainment in the world, than dry truth and real knowledge, figurative speeches and allusion in language will hardly be admitted as an imperfection or abuse of it» (Locke, 1908: II, 112). Aunque el anatema de Locke sobre la metáfora haya sido levantado en la actualidad y la filosofía contemporánea conceda un papel cognoscitivo fundamental a figuras como la metáfora y la metonimia, en el caso de la alusión estamos ante un tema condenado aún al ostracismo. Y ello a pesar de que la alusión es un recurso usado por filósofos de todas las tendencias, los cuales es de esperar que pretendiesen hacer algo más de divertir o ser ingeniosos cuando la han usado. 


\section{Delimitación y ejemplos de Alusión.}

Dado que, ni los diccionarios generales de filosofía ni los más especializados de filosofía del lenguaje o lingüística, proporcionan ninguna definición de alusión, tendré que recurrir a dos diccionarios especializados, uno de términos literarios y otro de retórica, para poder establecer alguna definición operativa de alusion. Así, The Concise Oxford Dictionary of Literary Terms, de Ch. Baldick, define la alusión como "an indirect or passing reference to some event, person, place, or artistic work, the nature and relevance of which is not explained by the writer but relies on the reader's familiarity with what is thus mentioned» (Baldick, 2001: 7). Por su parte, el Diccionario de retórica y poética, de H. Beristáin, define la alusión como «figura de pensamiento que consiste en expresar una idea con la finalidad de que el receptor entienda otra, es decir, sugiriendo la relación existente entre algo que se dice y algo que no se dice pero que es evocado» (Beristáin, 1995: 38-39).

De acuerdo con estas definiciones podemos inferir que una alusión tendría las siguientes características:

1. Sería una referencia indirecta a cualquier texto, idea, individuo o fenómeno del mundo.

2. Requiere que quien hace la alusión sepa (o crea saber) que el oyente/ lector tiene capacidad para identificar al individuo o fenómeno aludidos.

3. No se trata de una mera figura ornamental o literaria, sino que tiene funciones cognitivas relevantes que permiten calificarla como "figura de pensamiento».

El que la alusión se haga en el ámbito del lenguaje ordinario, de un texto filosófico, literario o científico o en un discurso parlamentario, o que tenga una función crítica, laudatoria o eufemística, por ejemplo, sería algo secundario o accidental que no afectaría al hecho de que una proferencia o un texto sean alusiones de pleno derecho. Para ver cómo funciona la alusión, nada más aconsejable que recurrir y analizar algunos ejemplos concretos:

(1) «La voluntad es lo genérico, así como la inteligencia lo individuante en el hombre, que el foco, Brennpunkt, de aquélla son los órganos genitales. Todo español sabe de dónde le salen las voliciones enérgicas» (Unamuno, 1916: 113. Primer énfasis del original, segundo mío). 
(2) «No se había curado Sancho de echar sueltas á Rocinante, seguro de que le conocía por tan manso y tan poco rijoso, que todas las yeguas de la dehesa de Córdoba no le hicieran tomar mal siniestro» (Cervantes Saavedra, 1911: II, 15. Énfasis mío).

(3) «Le bon sens est la chose du monde la mieux partagée : car chacun pense en être si bien pourvu, que ceux même qui sont les plus difficiles à contenter en toute autre chose, n'ont point coutume d'en désirer plus qu'ils en ont» (Descartes, 1897a: 2-3. He modernizado la grafía).

(4) «En ciencia tiene valor precisamente lo que se puede repetir: mas el estilo es siempre unigénito. Yo siento, por esto, una religiosa emoción cuando en la lectura de obras poéticas recientes (...) me parece sorprender más allá de las virtudes de plenitud, armonía y corrección, el vagido inicial de un estilo que germina» (Ortega y Gasset, 1983a: 263. Énfasis mío).

(5) «But criticism, when once invited, is apt to extend much further than the most daring, at first, would have wished. 'First cut the liquefaction, what comes last,/But Fichte's clever cut at God himself?' ' So it has been with Geometry. The liquefaction of Euclidean orthodoxy is the axiom of parallels» (Russell, 1897: 7. Énfasis mío).

Aunque (1) pertenece a un texto filosófico y (2) a un texto literario, ambos casos comparten la característica de referirse a fenómenos que Unamuno y Cervantes, respectivamente, suponen conocidos por la mayoría de los hablantes de la lengua castellana. En (1) se alude a una expresión coloquial -y probablemente considerada malsonante por muchos, aunque muy usada - que se supone que cualquier hablante español podrá identificar gracias al contexto de la proferencia y a la alusión eufemística unamuniana, incluso aunque un hablante dado nunca la hubiese usado por considerarla tabú o indecorosa ${ }^{3}$. En (2), por su parte, se alude al hecho del prestigio, por su belleza y capacidades reproductivas, que tenían las yeguas de las dehesas cordobesas sobre el resto de las yeguas españolas, al menos desde que Felipe II instituyó en las dehesas cordobesas del Guadalquivir unas

2 Nótese que, lo mismo en el texto citado que en texto original de Browning, el adjetivo «himself» está escrito con minúsculas, lo que no deja de ser chocante en palabras puestas en la boca de un obispo.

3 «Il faut prêter attention à la nature de cette interdiction qui porte non sur le 'dire quelque chose' qui serait une opinion, mais sur le 'prononcer un nom' qui est pure articulation vocale. C'est proprement le tabou linguistique : un certain mot ou nom ne doit pas passer par la bouche. Il est simplement retranché du registre de la langue, effacé de l'usage, il ne doit plus exister. Cependant, c'est là une condition paradoxale du tabou, ce nom doit en même temps continuer d'exister en tant qu'interdit» (Benveniste, 1974 : 255). 
caballerizas reales en 1567, o, quizás, Felipe II instituyó allí sus caballerizas reales porque ya gozaban de prestigio las yeguadas cordobesas (Cfr. García Cano, 2017).

Por su parte, (3), (4) y (5) son textos alusivos dirigidos a un grupo reducido de lectores en la media en que, para identificar lo aludido en ellos, se requiere un cierto grado de conocimiento que iría más allá de la formación que suponemos a un lector/hablante estándar. Efectivamente, (3) - que son las palabras inaugurales de la obra seminal de la filosofía moderna, el Discurso de método - es una alusión a un texto de los Ensayos, de M. de Montaigne ${ }^{4}$, que se pone al principio de la obra cartesiana para señalar la filosofía que Descartes se propone desterrar con todas sus fuerzas (Chamizo Domínguez y Rojas Jiménez, 2019: 243) y que, a su vez, pudiera ser un eco de textos platónicos (Gilson, 1987: 82-84). Esto es, Descartes comienza su ensayo en francés, que es el Discurso del método, con una referencia anónima a Montaigne porque sabe (o confía en) que sus lectores van a ser capaces de identificar el texto aludido. Y, como toda alusión, el texto cartesiano es esencialmente ambiguo, de manera que la posterioridad lo va a interpretar, ora como un precedente de «l'égalité épistémique» (Marcil-Lacoste, 1988), ora como una ironía «que n'est pas la proclamation du principe d'égalité politique» (Quillien, 1994: 27).

Por su parte, en (4), Ortega califica al estilo literario con un adjetivo que evoca directamente al Hijo de Dios y que es el calco latino del término

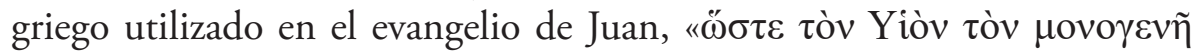
¿ $\delta \omega \kappa \varepsilon v »(J u a n, 3: 16)$. Este texto, que la Vulgata tradujo como «ut Filium suum unigenitum daret», se puede considerar como uno de los dogmas centrales del cristianismo, si no el dogma central, por antonomasia. Con ello, Ortega encuadra su consideración del estilo literario en un contexto cuasi religioso, que muy pocos lectores están capacitados para comprender $y$, entre los lectores capacitados para comprender la alusión orteguiana, es probable que sea más significativa para aquellos que crean en el dogma religioso que para aquellos que no crean en él ${ }^{5}$. En todo caso, es obvio

4 «On dit communément que le plus juste partage que nature nous ait fait de ses grâces, c'est celui du sens : car il n'est aucun qui ne se contente de ce qu'elle lui en a distribué» (Montaigne, 2002: 479).

5 Incluso para quienes crean en ese dogma religioso, la alusión orteguiana tendrá distinta fuerza de evocación en función de la traducción con la que esté familiarizado. Así, por ejemplo, es razonable pensar que la evocación religiosa de (5) será más potente para qui- 
que el significado de (4) no será el mismo para un cristiano (para quien se trata de un asunto central para su fe), para un musulmán o un judío (que son estrictamente monoteístas y probablemente consideren el texto del Evangelio de Juan como una blasfemia) o para un politeísta (para quien no sería nada sorprendente que una divinidad tenga hijos).

Finalmente, (5) es especialmente interesante en la medida en que tiene dos características que lo diferencian de los cuatro ejemplos anteriores; 1) la alusión está entrecomillada; y 2) el texto aludido alude, a su vez, a dos fenómenos distintos. Dado que, en (5), se recogen literalmente las palabras de otra obra, el poema «Bishop Blougram's Apology», de Robert Browning (2007: 200), este texto sería un caso limítrofe entre una alusión y una cita. De hecho, lo único que hubiese faltado para que podamos considerar una cita a los dos versos entrecomillados es que B. Russell hubiese añadido el nombre de su autor. En cuanto a las dos alusiones contenidas en estos versos, la primera es a la licuefacción de la sangre de San Genaro, que acontece en Nápoles en algunas festividades señaladas, especialmente el 19 de septiembre de cada ańo, que es el día del santo. Esta primera alusión es relativamente fácil de descifrar en la medida en que, unas líneas antes, el propio Browning ha atribuido al obispo Blougram la sospecha de que «The Naples' liquefaction may be false» (Ibídem), que, a su vez, sería otro caso de alusión ${ }^{6}$. Pero, por el contrario, no hay ninguna información contextual en el poema de Browning para la segunda alusión que permita descifrarla. Siendo las cosas así, identificar en qué pueda consistir el «Fichte’s clever cut at God himself» tiene dos características que son consustanciales con toda alusión: 1) la indeterminación de su interpretación, y 2) la necesidad de una colaboración activa por parte del lector para desentrañar lo que el autor del texto quiso o pudo querer decir. La indeterminación de la interpretación viene dada en la medida en que una alusión es, por su propia esencia, un

en esté familiarizado con la versión del texto griego como «que le dió (sic) su Unigénito Hijo" (Sagrada Biblia, 1944) que para quien esté familiarizado con la versión de "que dio a su Hijo único» (Nueva Biblia Española, 1975).

6 Sorprendentemente, el traductor francés de esta obra se vio en la obligación de especificar en qué consistía esta alusión y escribir que se trataba de una «allusion au miracle de la liquéfaction du sang de saint Janvier, qui se produit à Naples à certaines dates fixes, notamment le 19 septembre» (Russell, 1901: 9, nota 1), pero no sintió la misma obligación con respecto a la alusión a Fichte. Por su parte, el traductor espańol se limita a copiar el original inglés en el texto y traducirlo en nota a pie de página (Russell, 1973: 16). 
ejemplo paradigmático de opacidad referencial. De manera que, un caso como la frase "Fichte's clever cut at God himself» es lo suficientemente imprecisa como para que esté indeterminado en qué pudiese consistir ese «tajo» que asestó Fichte al mismo Dios. Y justamente por esta opacidad referencial de toda alusión es por lo que se requiere un papel activo por parte del oyente/lector, que debe aplicar el Principio de Caridad y el Principio de Cooperación con objeto de optimizar lo que el hablante/autor quiso significar cuando usó una alusión y no una proferencia directa y literal. Precisamente por ello — a lo que habría que añadir el hecho de que esta es la única vez que Browning cita a Fichte en toda su obra- es por lo que esa frase se ha interpretado de formas diversas ${ }^{7}$.

\section{LA ALUSIÓN Y LOS MECANISMOS LINGÜÍSTICO-COGNITIVOS CERCANOS.}

Una buena manera de aproximarse para aquilatar una concepción filosófica de la alusión quizás sea la de contrastarla con los fenómenos lingüístico-cognitivos que le son más cercanos con objeto de delimitar y distinguir la una de los otros. Desde el análisis de textos literarios - y en esto un texto filosófico o científico no difiere grandemente de cualquier texto literariola alusión sería un caso particular de intertextualidad, o «relation de coprésence entre deux ou plusieurs textes, c'est-à-dire, eidétiquement et le plus souvent, par la présence effective d'un texte dans un autre» (Genette, 1982: 14). ${ }^{8}$ Desde este punto de vista, la alusión, la cita y el plagio (Genette, 1982: 13-14; Martínez Alfaro, 1996: 280-281) serían casos particulares de intertextualidad. Esto es, la alusión, la cita y el plagio serían casos de hiponimia con respecto a la intertextualidad, que sería un término supe-

7 Así, para los editores de la obra citada de Browning, la alusión a Fichte sería «perhaps a reference to the controversy which followed the publication of Fichte's 1798 essay 'On the Foundation of our Belief in a Divine Government of the Universe' (that...) resulted in accusations of atheism and the loss of his post at the University of Jena» (Browning, 2007: 200, nota), mientras que para otros -sin negar la acusación de ateísmo- el tajo de Fichte al propio Dios aludiría «to an expression attributed to Fichte: 'Gentlemen, in tomorrow's lecture we will create God.'», frase con la que Fichte se habría despedido de sus alumnos al terminar una de sus clases (Brother Azarias, 1904: 92).

8 Prescindo de nociones más elaboradas de intertextualidad como la de Roland Barthes, que, llevando a sus extremos el estructuralismo saussureano, prescinde del autor para centrarse exclusivamente en la relación entre textos que «derive their meanings, not from some author creating de novo and ex nibilo, but only through their relations to other texts» (Irwin, 2004: 230). 
rordenado. Para otros estudiosos del tema, alusión e intertextualidad serían casos de sinonimia (Machacek, 2007: 523-525).

Para que una proferencia/texto determinado se considere una cita, sea esta en estilo directo o indirecto, literal o al sentido, es condición inexcusable que el hablante/autor haga referencia explícita a las palabras o ideas de algún otro a quien se considera su autor y que tales palabras se reproduzcan fielmente, sea para avalarlas, sea para criticarlas o mostrar algún desacuerdo con ellas. Esto es, una cita requiere la intención de quien cita de ser lo más fiel posible a la proferencia/texto original y de hacer explícito el nombre de su autor. Hasta tal punto debe ser esto así, que, incluso cuando hay un error manifiesto en la proferencia/texto original, quien cita está obligado intelectual y moralmente a hacerlo notar, al igual que también está obligado a hacerlo notar cuando el hablante/autor ha enfatizado alguna o algunas de sus palabras. En otras palabras, una cita ideal debería cumplir con los siguientes requisitos: 1) que se haga explícito el nombre del autor de la proferencia/texto original; 2) que se reproduzcan literalmente las palabras (o, al menos, se respete escrupulosamente su significado, si se trata de una cita al sentido) del proferencia/texto original; 3) que se proporcione la información suficiente para que el lector pueda verificar por sí mismo la exactitud de lo citado; y 4) que el autor de la cita no asuma que el oyente/lector conoce ya de antemano lo citado.

Por su parte, el plagio sería aquel caso de intertextualidad que, prima facie, consistiría en «a departure from the convention of attribution of sources» (Woolls, 2006: 627), aunque con importantes ramificaciones legales y morales, además de las meramente intelectuales o académicas. Desde el punto de vista estrictamente académico, el plagio sería «un emprunt non déclaré» (Genette, 1982: 14), del cual, asumimos, que el plagiario (o la plagiaria) es consciente. En consecuencia, el plagio diferirá de la cita justamente en el hecho de que el plagiario (o la plagiaria) se atribuye un texto o una idea de algún otro a quien no le reconoce la paternidad del texto o idea en cuestión. La diferencia entre plagio y alusión no radicaría, las más de las veces, en la mayor o menor similitud entre dos textos o proferencias, sino en que atribuyamos al plagiario la voluntad de ocultar sus fuentes, mientras que tal voluntad no se la atribuimos a quien hace una alusión. Al igual que también descartamos como plagio y como alusión el mero eco de una obra en otra posterior, de modo que la 
similitud entre dos textos no obedecería más que al hecho de que, en el eco, el segundo autor haya asumido las palabras o ideas del primero hasta el punto de que no tenga conciencia de que las ha tomado de otro. Cuando M. de Montaigne escribe "Il y a ignorance abécédaire qui va devant la science ; une autre, doctorale, qui vient après la science : ignorance que la science fait et engendre, tout ainsi comme elle défait et détruit la première» (Montaigne, 2002: 234), parece obvio a cualquier conocedor de la tradición filosófica que la expresión ignorance doctorale evoca casi automáticamente a la expresión docta ignorantia acuñada por Nicolás de Cusa, cuya obra sabemos positivamente que era conocida por Montaigne 9 . Ahora bien, aunque es sorprendente que Montaigne no mencione en este caso al Cusano dado lo abundantemente que solía citar sus fuentes, el texto citado no puede ser considerado ni un plagio ni una alusión. Lo primero porque no atribuimos a Montaigne la voluntad de ocultar el origen del término; lo segundo porque aceptamos que la expresión docta ignorancia estaba ya lo suficientemente difundida como para que su uso pudiera considerarse mostrenco. En todo caso, se trataría simplemente de una reminiscencia de la lectura de las obras del Cusano y del uso de una expresión afortunada que, por lo demás, Montaigne utiliza en un contexto filosófico distinto del contexto en el que se acuñó esta expresión.

A veces las reminiscencias o ecos de diversas lecturas pueden inducir al oyente/lector a apreciaciones erróneas. En una de las muchas traducciones al castellano del Discurso del método, de Descartes, podemos leer lo siguiente:

(6) «Ni siquiera quise empezar a rechazar por completo ninguna de las opiniones que en otro tiempo hubieran podido deslizarse en mi creencia sin pasar por el tamiz de la razón» (Descartes, 2008: 21-22. Énfasis mío).

En principio, el modismo pasar algo por el tamiz — cuyo significado en cuanto modismo es "examinarlo o seleccionarlo concienzudamente» (DLE, 2019) — bien pudiera ser la traducción del modismo francés passer par l'étamine —cuyo significado es «soumettre à un examen critique très pointilleux, faire subir une sélection très sévère» (CNRTL, 2019)— y este

9 De hecho, en los Ensayos no aparece citado ni una sola vez. No obstante, sabemos, por confesión propia, que Montaigne poseía las obras de Nicolás de Cusa, las cuales había adquirido durante su viaje a Italia: «Il a laissé à Padoue, sur cet'esperance, à un maistre François Bourges, François, les œuvres du Cardinal Cusan, qu'il avoit acheté à Venise» (Montaigne, 1909: 170). 
último bien hubiera podido ser utilizado por el propio Descartes, pues ya aparece usado por Montaigne en el ensayo «De l'intitution des enfants» ${ }^{10}$, cuando aconseja que el educando examine concienzudamente cualquier doctrina u opinión antes de aceptarla y hacerla suya. Ahora bien, el caso es que Descartes no utiliza en ningún lugar de su obra el modismo passer par l'étamine y que (6) es traducción de

(6.1) «Même je ne voulus point commencer à rejeter tout à fait aucune des opinions qui s'étaient pu glisser autrefois en ma créance sans y avoir été introduites par la raison» (Descartes, 1897a: 17. He modernizado la grafía. Énfasis mío).

Dadas estas circunstancias, es probable que el traductor de (6) haya utilizado el modismo pasar por el tamiz porque creyese que recoge mejor el pensamiento cartesiano que la mera traducción literal del verbo francés original introduire por el castellano introducir. Pero, cualquier lector castellano de (6), al que bien se puede imaginar desconocedor de (6.1), pero sí conocedor del texto de Montaigne ${ }^{11}$, bien pudiera entender que - al igual que hace en otros varios sitios- Descartes estaba aludiendo o haciéndose eco de un texto de Montaigne. Pero lo cierto es que es el traductor al castellano del texto cartesiano, y no el propio Descartes, quien se hace eco de un texto de Montaigne.

Una clase particular de atribución (fraudulenta) de autoría, a la que no se suele prestar demasiada atención excepto en los estudios de traductología, es la de las traducciones que no se llevan a cabo directamente de la lengua original, sino de una lengua intermediaria. En estos casos, obviamente, no se oculta al autor original del texto, pero sí al traductor intermedio, siendo el caso en que es posible detectar traducciones que divergen de lo dicho en el texto de la lengua origen, pero no de otras traducciones previas a otras lenguas. Consideremos el caso del siguiente texto:

(7) «(Und das Wörterbuch übersetzt nicht nur Substantiva, sondern auch Zeit-, Eigenschafts- und Bindewörter etc.; und es behandelt sie alle gleich.)»(Wittgenstein, Tractatus, 4.025. Énfasis mío).

10 El texto de Montaigne dice exactamente: «Qu'il lui fasse tout passer par l'étamine et ne loge rien en sa tête par simple autorité et à crédit» (Montaigne, 2002: 120).

11 De hecho, el texto de Montaigne citado en la nota anterior se ha traducido como: "Que haga que todo lo pase por su tamiz sin alojarle cosa alguna en la cabeza por simple autoridad y crédito» (Montaigne, 2005: 186). 
Los sustantivos alemanes Zeitwort, Eigenschaftswort y Bindewort significan, respectivamente, verbo, adjetivo y conjunción. Dado que son términos técnicos del sociolecto gramatical y, además, monosémicos, su traducción al castellano - salvo por el hecho de que tienen un cierto saber arcaico y que hoy en día suelen sustituirse por los términos Verb, Adjektiv y Konjunktion, respectivamente- no parece que presente especiales problemas. Y, sin embargo, la primera versión del Tractatus que se publicó en castellano traducía (7) como

(7.1) «(Y el diccionario no traduce sólo los substantivos, sino también los adverbios, conjunciones, etcétera; y trata todo del mismo modo.)»(Wittgenstein, 1979: 77. Énfasis mío).

La comparación de (7.1) con (7) pone de manifiesto que, por una parte, los sustantivos Zeitwort y Eigenschaftswort no se han traducido al castellano, mientras que, por otra parte, se ha añadido el sustantivo castellano adverbio, cuyo equivalente alemán en la terminología arcaizante de Wittgenstein sería *Umstandswort y que no aparece en (7). En un principio, se podría aventurar la hipótesis de que las divergencias entre (7) y (7.1) pudieran estar originadas en algún lapsus por parte del traductor al verter el texto del alemán al castellano. Pero esta hipótesis se debilita cuando se compara (7.1), no con el texto original alemán, sino con la primera traducción al inglés:

(7.2) «(And the dictionary does not only translate substantives but also adverbs and conjunctions, etc., and it treats them all alike.)»(Wittgenstein, 1922: 69. Énfasis mío).

$\mathrm{Si}$, aplicando la navaja de Ockham, descartamos por improbable que se haya dado una infeliz coincidencia debida a alguna armonía preestablecida que hubiese hecho que (7.1) coincidiese exactamente con (7.2) y ambos difiriesen de (7) exactamente en lo mismo, entonces la explicación más sencilla será la de suponer que (7.1) es traducción de (7.2) y no del original alemán ${ }^{12}$.

12 Por lo demás, no es este el único ejemplo que se puede aducir. Baste citar un segundo caso para reforzar la verosimilitud de la hipótesis que estoy contemplando. De nuevo, la frase "Filosofía no es teoría, sino actividad» (Wittgenstein, 1979: 85. Énfasis mío) se parece más a "Philosophy is not a theory but an activity» (Wittgenstein, 1922: 77. Énfasis mío) que a "Die Philosophie ist keine Lehre, sondern eine Tätigkeit» (Tractatus, 4.112. Énfasis mío). Y ello porque, así como en alemán el sustantivo Philosophie está acompaña- 
En resumen, desde el punto de vista desde el que estoy considerando la alusión, se podría mantener que el criterio para distinguir la alusión del plagio, la cita y el eco no obedece tanto a la literalidad del texto o idea de un primer hablante/autor reproducidos por un segundo, sino a la intención con que se hace y a las expectativas que tiene con respecto al oyente/lector. Y, por parte del oyente/lector, el calificar a algo como alusión o plagio puede obedecer más a las expectativas sobre la honradez del hablante/autor que a razones objetivas, como pueda ser la mayor o menor literalidad de lo reproducido sin citar su origen ${ }^{13}$. Así, un plagio sería la apropiación y reproducción con un alto grado de literalidad que hace un hablante/autor de una proferencia/texto (o, en su caso, una idea) de otro con la intención de presentarlo como propio y con la expectativa de que el oyente/lector no sea capaz de identificar al autor original de la proferencia/texto en cuestión. La mayor o menor longitud del texto en cuestión sería irrelevante para efectos intelectuales, aunque sí lo pudiera ser para efectos legales ${ }^{14}$. La cita comparte con el plagio el hecho de tratarse de la reproducción literal de una proferencia/texto, pero con mención expresa del autor (u obra, en caso de una obra sin autor conocido) y proporcionando todos los medios necesarios para que el oyente/lector pueda identificar la veracidad de lo que se cita $^{15}$. El eco, por su parte, sería una cita de la que el autor ha perdido

do por el artículo determinado - y lo esperable es que esto se hubiese hecho también en castellano de haberse vertido directamente el texto, dado que el uso del artículo determinado en castellano es muy similar a su uso en alemán- en el texto inglés (por las exigencias de la propia lengua inglesa) el artículo determinado ha desaparecido. Como consecuencia de ello, también ha desaparecido en castellano, donde la aseveración «Filosofía no es teoría, sino actividad» resulta, cuando menos, extraña, si no de dudosa gramaticalidad. Por el contrario, las otras versiones castellanas posteriores del mismo texto sí han incluido el artículo determinado: "La filosofía no es una teoría, sino una actividad» (Wittgenstein, 2003: 161. Énfasis mío), "La filosofía no es una doctrina, sino una actividad» (Wittgenstein, 2009: 45, y Wittgenstein, 2016: 78. Énfasis mío).

13 De hecho, si el ejemplo (3) se considera un caso de alusión y no de plagio puede que la razón principal para ello radique solamente en nuestras expectativas sobre las intenciones de Descartes y no en la literalidad del propio texto.

14 En este sentido, y para evitar complicaciones legales, hay editoriales que exigen a sus autores que se soliciten los permisos pertinentes cuando en una obra citan más de 100 palabras seguidas de otra obra publicada, incluso en el caso de que se haya identificado perfectamente el texto citado.

15 Cuando no se cumple rigurosamente con los criterios de una cita y se fía uno a la memoria, por ejemplo, puede acontecer que lo citado sea erróneo o no verificable. Este es el 
conciencia de la autoría original, de puro haber hecho suyo el pensamiento o expresión de que se trate ${ }^{16}$. Desde el punto de vista del oyente/lector, así como el proceso de la identificación de un plagio se dispara porque este sospecha que ha habido una falta de honradez o sinceridad en el hablante/ autor, cuando a un texto lo consideramos como un eco de otro -incluso en los casos en los que se pueden identificar reproducciones bastante literales - damos como aceptado el que el autor del segundo texto ha obrado de buena fe y no ha sido consciente de estar reproduciendo un texto ajeno de puro asumido que tiene lo que se dice en él. Finalmente, la alusión sería una referencia a un texto, idea, objeto o individuo que no se nombran expresamente porque el hablante/autor tiene la expectativa de que el oyente/lector es capaz de identificar lo aludido. Cuando esto no ocurre, la alusión pierde buena parte de su función cognoscitiva.

Aunque en la bibliografía al uso no se suele hacer referencia a esto, ni tan siquiera en los escasos trabajos que se aproximan a la alusión desde el punto de vista de la pragmática filosófica del lenguaje (Perri, 1978), la alusión comparte muchas de sus características con la implicatura conversacional.

Una implicatura consiste básicamente en el hecho de que, por una parte, lo que el hablante implica, sugiere o quiere decir es distinto de lo que literalmente dice (Grice, 1989: 24), pero, por otra parte, sabiendo (o esperando) que el oyente tiene la suficiente competencia como para encontrar o calcular lo que el hablante quiere decir (Grice, 1989: 31). Y esto se cumple adecuadamente en la alusión, donde también el hablante se refiere a un hecho o un texto, que no nombra o identifica con claridad porque espera que el oyente pueda hacerlo por sí mismo. De ahí que

caso, por ejemplo, del famoso texto orteguiano «Yo soy yo y mi circunstancia, y si no la salvo a ella no me salvo yo. Benefac loco illi quo natus es, leemos en la Biblia», que, para más inri, Ortega repite dos veces (1983b: 322 y 1983d: 44), donde la frase latina atribuida a la Biblia no aparece en ninguna parte de la Vulgata.

16 Un caso particular de este fenómeno sería el de los nombres de leyes o teoría científicas, a los que, en muchos casos, solemos referirnos, bien por el nombre de quien las propuso por primera vez, bien por un resumen de su contenido; y no porque no nombremos a quien propuso por primera vez una ley o una teoría científica, lo consideramos un caso de plagio. De ahí que, para la cuestión que se está considerando, sea indiferente que hablemos de la Ley de las proporciones definidas o de la Ley de Proust, la Ley de las proporciones múltiples o Ley de Dalton, la Ley de la irreversibilidad evolutiva o Ley de Dollo, o, el Postulado de las paralelas o el V Postulado de Euclides. 
la alusión se haya descrito como un proceso compuesto por dos pasos diferentes: la referencia alusiva, que implica que uno se está refiriendo a algo, y la implicación alusiva, que es la implicación de una proposición adicional no explicitada (Coombs, 1984: 477) y que sería la que debe identificar el oyente. $\mathrm{Y}$, al igual que fracasa el intento de que un oyente haga una implicatura cuando este no es o no quiere ser cooperativo, el efecto cognoscitivo de una alusión fracasa cuando el oyente/lector no puede ser cooperativo porque desconozca el hecho o texto aludidos. En la alusión, como en la implicatura, será el ajuste o desajuste entre lo que el hablante supone que el oyente sabe y lo que este último sabe realmente lo que dé como resultado el éxito o fracaso en la comprensión del mensaje. Precisamente porque el éxito de una implicatura y el de una alusión dependen de los conocimientos compartidos por hablante y oyente es por lo que se ha podido hablar de que la alusión está íntimamente conectada con lo que se ha llamado "the cultivation of intimacy» (Irwin, 2001: 296, n. 8), aplicando al tema de la alusión un concepto que se había acuñado para definir la metáfora (Cohen, 1978) y el chiste (Cohen, 1999: 28-29). En cierto modo, el éxito de una implicatura y de una alusión dependerán de que el oyente tenga una especie de libreta de claves que le permita interpretar correctamente lo dicho por el hablante de acuerdo con un código tácito compartido. Esto hace que una alusión sea una especie de guiño que hace un hablante/autor a un oyente/lector al que, por decirlo así, le puede hablar en una clave que no entenderían otros individuos.

Así como para que una implicatura tenga éxito el hablante debe saber o creer que el oyente tiene determinados saberes, opiniones o creencias que le permitan hacer la inferencia relevante y pertinente en un contexto dado, el hablante/autor que hace una alusión solamente podrá esperar tener éxito, esto es, podrá esperar que sea adecuadamente comprendida cuando sepa (o crea saber) que el oyente/lector comparte determinados saberes, creencias, opiniones o usos sociales con él. Justamente por ello, en la misma medida en que aumente la distancia intelectual, cultural o temporal entre hablante y oyente aumentará también la dificultad para comprender exactamente el alcance cognoscitivo de una alusión. Y, viceversa, en la medida en que esas distancias se acorten, las posibilidades de comprender con exactitud el alcance cognoscitivo de una alusión aumentarán. Quizás por ello Ortega, cuya obra está plagada de alusiones, confesase que, puesto que nunca había 
sido presentado al «hombre en general», podía escribir sobre él como podía hacerlo sobre el ornitorrinco, pero no podía escribirle a él, pues «no conozco al 'hombre en general', no sé quién es, y en la medida en que sospecho quién es, he procurado evitarlo siempre» (Ortega y Gasset, 1983d: 19).

Es más, se podría decir que una implicatura necesita de una alusión previa explícita, o de una presuposición no explícita, para que pueda llevarse a cabo. Así, por ejemplo, el propio ejemplo griceano «You are the cream in my coffee» (Grice, 1989: 34), funciona en la medida en que en ciertos países es costumbre añadir nata al café, pero difícilmente funcionará en aquellos otros en que sus habitantes no tengan esta costumbre. Precisamente por esta razón, el traductor al castellano de «Logic and Conversation» tradujo el ejemplo original como «Eres la niña de mis ojos» (Grice, 1991: 524) ${ }^{17}$. En otros términos, para comprender en todo su alcance el ejemplo griceano, Grice contaba con que sus lectores conocían (o podrían conocer) los siguientes datos, al menos: 1) que el propio ejemplo es por sí mismo una alusión; y 2) que los lectores de «Logic and Conversation» acostumbraban a añadir nata al café, lo cual es una alusión a una determinada costumbre social. Para un lector distante cultural o temporalmente de Grice, puede que el alcance completo de estas alusiones se le escape y lo que quiso significar Grice al poner ese ejemplo concreto, y no cualquier otro, para ilustrar cómo la metáfora y la ironía burlan la máxima de cualidad no sea comprendido en su amplitud y la intimidad entre Grice y sus lectores se rompa. De ahí que, cuando pasa el tiempo en un texto en el que se recurre a alguna alusión, los editores o los comentaristas del texto tengan que hacer explícita la alusión de que se trate con objeto de que los lectores puedan aquilatar lo más posible el contenido cognoscitivo del texto ${ }^{18}$. Y lo mismo acontece cuando la distancia es cultural o cuando dos hablantes discrepan con respecto a un mismo hecho.

Quizás donde se vea con toda nitidez cómo una determinada alusión puede dejar de comprenderse o ser comprendida de forma diferente a como

17 Yo, por mi parte, propuse traducir el ejemplo griceano como «Tú eres la miel de mi vida» (Chamizo Domínguez, 1988).

18 Así, por ejemplo, el que los títulos de dos obras filosóficas tan conocidas como son How to Do Things with Words, de J. Austin, y From a Logical Point of View, de W. van O. Quine, son sendas alusiones, la primera a los títulos de los libros de autoayuda y la segunda a un calipso de Trinidad es algo que hay que explicar, si se quiere saber, al menos, el proceso de gestación de ambas obras (Chamizo Domínguez, 2017: 48-53). 
(suponemos que) pretendió el autor del texto original es cuando ese texto hay que traducirlo a otra cultura o cuando pasa sobre él el tiempo. Este sería el siguiente ejemplo, en el que el jefe galo Abraracourcix arenga a sus paisanos para que hagan pagar a los romanos una afrenta que les habían infringido:

(8) «Gaulois, gauloises!.. Nous devons donner une bonne leçon aux romains, par Toutatis!» (Goscinny \& Uderzo, 1964a: 9).

El hecho de que, en (8), el jefe galo recurra al uso del masculino y del femenino para dirigirse a sus paisanos se ha interpretado habitualmente como una alusión caricaturesca al general Charles de Gaulle, quien tenía por costumbre en sus discursos distinguir entre el masculino el femenino cuando se dirigía a los franceses (Fernández y Gaspin, 1991: 103). Dado que en la época era sumamente infrecuente que los políticos franceses incluyesen el masculino y el femenino en sus intervenciones públicas, la alusión era fácilmente interpretable y el individuo aludido era fácilmente identificable. Pero, con el paso del tiempo y la irrupción del lenguaje inclusivo, es muy probable que, en la actualidad - y en el caso de que (8) sea entendida como una alusión caricaturesca - la propia alusión tenga connotaciones cognitivas distintas y que el individuo al que se identifique como aludido sea alguien cuyas ideas políticas y las razones que pudiera tener para recurrir al masculino y al femenino sean muy distintas a las que pudiera haber tenido el general Charles de Gaulle.

Y algo análogo a lo que pasa con el transcurso del tiempo dentro de un ámbito lingüístico y cultural dado, acontecerá cuando se trate de traducir (8) a otras lenguas. De hecho, y a pesar de que no hubiese habido ningún problema estrictamente lingüístico para mantener la inclusión de ambos géneros gramaticales en inglés y en castellano, lo cierto es que, en las traducciones de (8) a ambas lenguas, este extremo fue obviado, bien porque los traductores no fuesen conscientes de la alusión contenida en (8), bien porque no creyesen necesario reproducirla justamente porque carecería de sentido y perdería su fuerza cognitiva en las lenguas término. El resultado es que (8) se tradujo al inglés y al castellano como:

(8.1) «Friends, Gauls, countrymen! We must give these Romans a good lesson, by Toutatis!» (Goscinny \& Uderzo, 1964b: 9).

(8.2) «¡Oh galos, mis valientes galos! ¡Vamos a darles una lección a esos romanos, por Tutatis!» (Goscinny \& Uderzo, 1964c: 9). 
Y lo mismo que acontece con un texto humorístico, como es el caso de (8), puede acontecer con el más serio y sesudo texto filosófico. Probablemente haya pocas obras en toda la historia de la filosofía más cicateras con las citas de sus fuentes que el Tractatus Logico-philosophicus, de L. Wittgenstein, cosa que incluso justifica el propio Wittgenstein en el «Vorwort» (Wittgenstein, 1922: 26). Pero, por el contrario, esta obra está plagada de alusiones como la del siguiente texto:

(9) «Alle Philosophie ist „Sprachkritik“. (Allerdings nicht im Sinne Mauthners.)» (Tractatus, 4.0031).

El propio Wittgenstein no proporciona ningún otro dato sobre que sea en lo que pudiera consistir la noción de crítica del lenguaje en Mauthner ni vuelve a citar a Mauthner nunca más en esta obra. Como resultado de ello, en (9), estamos ante un caso parangonable a lo que sería un hápax en filología clásica. Y a ello hay que añadir que, dado que Wittgenstein define negativamente la noción de crítica del lenguaje de Mauthner y de una negación se puede seguir cualquier cosa, es probable que muy pocos lectores actuales de Wittgenstein puedan aquilatar el alcance de esta alusión, e, incluso, es muy poco probable también que los propios contemporáneos de la publicación del Tractatus lo hubiesen podido hacer. Precisamente por ello, los estudiosos de la obra de Wittgenstein se ven obligados a exponer en sus escritos el pensamiento de Mauthner justamente para poder aquilatar el alcance cognoscitivo de la alusión wittgensteiniana. Este es el caso, por ejemplo, de los autores de Wittgenstein's Vienna, quienes se vieron en la necesidad de dedicar un buen puñado de páginas de su obra (Janik y Toulmin, 1973: especialmente, 121-33, 165-168 y 178-82) para contextualizar y hacer comprensible la alusión de (9).

\section{LA ALUSIÓN COMO INCUMPLIMIENTO DE LAS MÁXIMAS CONVERSACIONALES GRICEANAS.}

Dado que, para que una alusión sea tal, es condición inexcusable el que no se haga explícita alguna información pertinente para la correcta y/o completa comprensión de lo dicho, una alusión incumpliría, al menos, dos máximas conversacionales, pero, a pesar de ello, cumpliría con el Principio de Cooperación: la máxima de cualidad y la máxima de modo. Puesto que la primera submáxima de la máxima de cualidad recomienda «Make your 
contribution as informative as is required (for the current purposes of the exchange)»(Grice, 1989: 26), toda alusión será una violación sistemática de esta submáxima en la medida en que el hablante oculta sistemáticamente (en todo o en parte) la información necesaria para que lo dicho por él pueda comprenderse plenamente. Así, en (5) — sea en la alusión de Russell a Browning, sea en el texto original del propio Browning-, la alusión a Fichte no es lo suficientemente informativa por cuanto que no se proporciona ningún dato adicional sobre aquello en lo que pudo consistir el tajo fichteano al mismo Dios. Y en la medida en que el hablante oculta sistemáticamente algún dato pertinente para la comprensión de su proferencia, la interpretación (correcta) de la alusión —como acontecerá, por lo demás, con figuras del lenguaje tales como la metáfora, la ironía, la meiosis o la hipérbole- estará sistemáticamente indeterminada. Ahora bien, la indeterminación del significado de las figuras del lenguaje radica en la ambigüedad semántica originada en el hecho de que una proferencia en la que se use una figura del lenguaje puede ser interpretada, al menos, de dos formas: literal y translaticiamente. En este sentido, una metáfora, por ejemplo, significa una violación de la segunda submáxima de la máxima de modo, "Avoid ambiguity» (Grice, 1989: 27), además de conllevar una falsedad categorial y de la violación de la máxima de cualidad. Así, en el ejemplo de metáfora que proporciona el propio Grice, "You are the cream in my coffee» (Grice, 1989: 34), cabe lo mismo una interpretación metafórica que una interpretación irónica, amén de una interpretación literal en contextos tales como el de una obra de ficción en la que se dotase de palabras y pensamientos a los objetos ${ }^{19}$.

Por su parte, la indeterminación del significado de una alusión tiene que ver también con la primera submáxima de modo, que recomienda evitar la ambigüedad, aunque no se trate principalmente de la ambigüedad semántica -como en el caso de las figuras del lenguaje- sino con la ambigüedad sintáctica o estructural. Y, además, la alusión viola también la segunda submáxima de modo, la que recomienda evitar la oscuridad, «Avoid obscurity of expression» (Grice, 1989: 27). Así como en una cita se

19 Conviene no olvidar que el propio ejemplo griceano es, en última instancia, una alusión a un musical de Broadway, de 1929, titulado Hold Everything en el que la aseveración «You are the cream in my coffee» sería susceptible de recibir una interpretación distinta de la que hace Grice (Musolff, 2017: 128). 
requiere que quien cita sea lo más preciso posible para facilitar al lector la verificación de lo afirmado o negado en la cita y que esto lo pueda hacer el oyente/lector con el mínimo esfuerzo y las menos presuposiciones posibles, en la alusión se trata justamente de conseguir lo contrario. Esto es, que el oyente/lector ejercite su imaginación interpretativa porque el hablante/ autor se ha expresado vagamente y no a causa de ninguna deficiencia del oyente/lector. Es más, para que la alusión cumpla con su función cognitiva el hablante/autor cuenta, consciente o inconscientemente, con la competencia del oyente/lector. La diferencia entre ambigüedad y opacidad referencial se puede hacer patente en el análisis del siguiente texto:

(10) «Como este señor del que no se sabe que tenga otro don que el de hablar en titulares alarmantes con la misma naturalidad con que hablaba en prosa el bruto enriquecido de Molière» (Muńoz Molina, 1998: 94).

En (10) hay dos alusiones evidentes. La primera consiste en referirse a un conocido político nacionalista vasco de la época y a la sazón presidente del Partido Nacionalista Vasco, Xabier Arzallus, por su conocida habilidad para hacer declaraciones lo suficientemente alarmantes como para que fuesen titulares de los periódicos. Y la característica principal de esta alusión es justamente la de su indeterminación en la medida en que la aseveración «este señor del que no se sabe que tenga otro don que el de hablar en titulares alarmantes» es lo suficientemente imprecisa como para que recibiese el valor de verdad V si se predicase de más de un personaje público. Si fuese el caso que el conocimiento de lo que se afirma en (10) sobre ese personaje se hubiese generalizado, entonces el hombre que habla en titulares alarmantes, o cualquier otra expresión sinónima de esta, se podría convertir en una forma alusiva para designar, por antonomasia, al individuo en cuestión. Así, la figura de la antonomasia aparece como una forma muy frecuente de alusión, cuando es el caso de que, mediante una sinécdoque, nos referimos a un individuo o un objeto por alguna característica destacada que pueda tener. Así, por ejemplo, si nos referimos a I. Kant como el filósofo de Koenigsberg o, como se refirió peyorativamente a él A. Machado, como «iTartarín en Koenigsberg!» (Machado, 1988: 641)²0,

20 Para una exposición más amplia de las alusiones filosóficas —especialmente críticas para con las posturas racionalistas e idealistas - en Proverbios y cantares, de A. Machado, ver (Chamizo-Domínguez y Bretones-Callejas, 2005). Por lo demás, Machado era consciente y jugaba expresamente con la vaguedad de sus alusiones: «Todos creerán que mis 
lo hacemos porque, a pesar de la indeterminación de ambas expresiones, consideramos que el oyente/lector puede identificar suficientemente al personaje, al menos si se trata de un oyente/lector conocedor de la historia de la filosofía y de la lengua y/o literatura francesa ${ }^{21}$. La segunda alusión, la incluida en la frase «con la misma naturalidad con que hablaba en prosa el bruto enriquecido de Molière», es un caso paradigmático de ambigüedad sintáctica por agrupamiento; esto es, aquel tipo de ambigüedad originada en el hecho de que una misma estructura superficial se corresponda con dos o más estructuras profundas diferentes. Si a la ambigüedad sintáctica añadimos el hecho de la ambigüedad semántica del sustantivo castellano bruto $^{22}$, la estructura superficial «el bruto enriquecido de Molière» puede interpretarse como significando las estructuras profundas siguientes: 1) "Molière escribió sobre un necio que se había hecho rico», que sería una alusión a la necedad de Monsieur Jourdain, personaje principal de Le bourgeois gentilhomme, de Molière; 2) «Molière era un necio que se había hecho rico», que sería una alusión a la necedad del propio Molière; 3) «Molière era propietario de un cuadrúpedo que se había hecho rico», lo que podría ocurrir en el contexto de una obra de ficción; o 4) «Molière era un cuadrúpedo que se había hecho rico», lo que también podría ocurrir en el contexto de una obra de ficción.

\section{Características de la alusión.}

Dado que implicatura conversacional y alusión no solamente comparten las dos características básicas que las hacen posibles, que son la de

epigramas están escritos contra alguien. Tras ellos se pondrá un nombre, ¿quién sabe de quién? Tal vez de aquel a quien menos haya yo querido aludir. Nadie comprenderá que estos epigramas están escritos contra mí mismo. ¿y por qué no? Yo soy Tartarín, yo soy el grillo, el burro de la flauta ronca, y el caracol y todo lo demás» (Citado por García Wiedemann, 1995: 178).

21 Dado que el sustantivo tartarín no está lexicalizado en castellano, es muy poco probable que un hablante castellano sin especial preparación pueda identificar la alusión machadiana y percatarse de que, en realidad, Machado está refiriéndose alusivamente a Kant como fanfarrón o charlatán. Precisamente ese es el significado del sustantivo francés tartarin, término originado también en una alusión: «[P. allus. à Tartarin de Tarascon, héros de romans de A. Daudet] Hâbleur, fanfaron» (CNRTL, 2019. S.v. $\operatorname{tartarin}^{2}$ ).

22 Recuérdese que el sustantivo bruto, además de «necio, incapaz», cuando se aplica a los seres humanos, puede significar también «animal irracional, especialmente cuadrúpedo», cuando se aplica a animales (DLE, 2019). 
violar máximas conversacionales y fundamentarse en los conocimientos, creencias, opiniones o usos sociales compartidos entre hablante y oyente, sino que, en función de estas dos características que hacen posible la implicatura y la alusión, comparten también otras varias características, a saber, 1) ser cancelables; 2) no depender del significado convencional.

Como consecuencia de su opacidad referencial, toda alusión es susceptible de recibir más de una interpretación, lo que la hace indeterminada o vaga en cuando a su significado. A resultas de ello, aunque el oyente/lector sea cooperativo (y comprenda lo que el hablante/autor quiere significar), puede hacer un cálculo no previsto por el hablante/autor e identificar como aludido lo que no pretendía el hablante/autor que se identificase como tal. Así, en (1), la alusión unamuniana al lugar donde se originan las voliciones enérgicas puede ser identificado con una víscera distinta de aquella que Unamuno quería que identificásemos, si el lector de (1) es (o se hace el) mojigato.

Este podría ser también el caso de la alusión contenida en el siguiente texto orteguiano:

(11) «Si alguien cree en el racionalismo como se cree en la Virgen del Pilar, quiere decirse que ha dejado, en su fondo orgánico, de creer en el racionalismo» (Ortega y Gasset, 1983c: 170. Énfasis mío).

Dado que, mediante la comparación de (11), Ortega estaba pretendiendo ilustrar el hecho de cómo la fe acrítica en el racionalismo es justamente la negación de la racionalidad, es probable que, con la alusión a la creencia en la Virgen del Pilar, Ortega quisiese significar una creencia dogmática a la que ninguna duda pueda hacer mella. Pero, es posible también que Ortega estuviese aludiendo al dicho «iA Zaragoza o al charco!», que, según el cuento, fue la respuesta de un baturro de Tarazona, que iba a ver a la Virgen del Pilar por sus fiestas. El baturro fue convertido en rana y echado a un chaco por san Pedro cuando se negó a terminar una frase con un «si Dios quiere». Para comprobar el santo tiempo después si el baturro había recapacitado y, en su caso, poder convertirlo otra vez en ser humano, la respuesta del aragonés fue «A Zaragoza o al charco!», queriendo significar que su relación con la Pilarica estaba por encima de la propia voluntad divinidad. En este caso, la alusión no sería tanto al dogmatismo, sino a la tozudez. 
$\mathrm{Al}$ igual que las implicaturas, las alusiones son inferenciales. Esto es, son calculables a partir del significado de la expresión, los datos del contexto y/o los conocimientos generales de los hablantes y de la suposición de que se mantiene el principio de cooperación. Cuando faltan esas condiciones, las alusiones no tienen éxito.

Como consecuencia de lo anterior, una alusión es inseparable de su significado. Esto es, una alusión deja de serlo o se transmuta en otra distinta si la proferencia alusiva se expresa de otra manera. Esto es lo que acontece en el siguiente ejemplo:

(12) «Nous savons que la préface de la Phénoménologie est postérieure à la rédaction de l'œuvre. Elle a été écrite après coup, quand Hegel a pu lui-même prendre conscience de son 'voyage de découverte'» (Hyppolite, 1941: 11).

(12) es un ejemplo típico de un texto en el que se alude vagamente a algo, que se presupone conocido por J. Hyppolite y por sus lectores y a lo que, precisamente por conocido, no hace falta referirse de una forma más explícita. Y, con el uso del término voyage de découverte, J. Hyppolite está aludiendo a, marcando diacríticamente y traduciendo el término alemán Entdeckungsreise, que es el que habría usado el propio Hegel para describirle a sus estudiantes la Fenomenología del espiritu (Pinkard, 2018: ix). Con el uso de Entdeckungsreise Hegel parece estar aludiendo a los viajes a tierras incógnitas tan típicos de los siglos XVIII y XIX, a lo que también parece aludir su traducción al francés como voyage de découverte. En otras palabras, la alusión hegeliana aparece como una forma de conceptualizar metafóricamente el propio proceso de creación de la Fenomenología del espiritu. Ahora bien, (12) se ha vertido al castellano como:

(12.1) «Como se sabe, el prólogo a la Fenomenología es posterior a la redacción de la obra. Se escribió, pasado ya el tiempo, cuando el propio Hegel pudo tomar consciencia de su 'avance en descubierta'” (Hyppolite, 1974a: 7).

Dado que el término castellano avance en descubierta, no evoca ningún tipo de expedición de exploración geográfica, sino un tipo de acción en el campo de batalla consistente en que la infantería ataque una posición enemiga sin que la infantería atacante tenga ningún tipo de protección, Hegel estaría aludiendo a que su obra era una especie de ataque militar sin protección. Y, en ese caso, la conceptualización metafórica del proceso de creación de la Fenomenología del espiritu, no solamente sería castrense, 
sino también incluso bélico ${ }^{23}$. Aunque, en el caso de (12) y (12.1), es harto dudoso el que el término castellano avance en descubierta ${ }^{24}$ sea la mejor traducción del término francés voyage de découverte ${ }^{25}$, lo cierto es que, dado que suponemos que el lector de (12.1) no tiene por qué conocer (12), la interpretación de la alusión hegeliana será muy distinta en uno y otro caso.

Finalmente, al igual que la implicatura que se haga en un momento dado suele estar regida por la relevancia que pueda tener en cada momento lo dicho por el hablante, la interpretación de la alusión también está regida por lo relevante que consideremos que es una determinada interpretación en un momento dado. En el caso de los modismos, el uso consciente de ellos en determinados contextos por parte del hablante tiene como finalidad el que el oyente entienda su significado lexicalizado como modismo a la vez que lo entiende también como una alusión al significado literal de los términos que componen el modismo. De modo análogo, las frases con doble sentido funcionan como alusiones. Aquí se juega con el significado destacado y con el significado secundario. Esto es, en un contexto dado, el oyente entenderá que debe interpretar la proferencia de acuerdo con su significado como modismo, pero siempre será posible la interpretación literal, o viceversa. En otras palabras, en los casos de frases de doble sentido o de modismos, un significado evoca al otro. En casos como este, se puede mantener que lo aparentemente relevante (el significado de la proferencia como modismo) se superpone a la alusión que solamente es identificable

23 En castellano el término avance en descubierta aparece en contextos como el siguiente: «El acompañamiento que hizo con el vehículo fue determinante en la cobertura de sus compañeros en su movimiento de avance en descubierta hacia el enemigo apostado, llevando además el apoyo de fuegos del artillero de su vehículo hacia donde más se necesitaba, la zona más expuesta y comprometida sin pensárselo y con determinación no falta de prudencia» (Delgado Mateo, 2012: 33. Énfasis mío).

24 De hecho, el término voyage de découverte significa «long périple effectué jadis par les grands voyageurs qui se déplaçaient par terre ou par mer pour aller à la découverte et à la conquête de contrées nouvelles» (CNRTL, 2019. S.v. voyage). La traducción como avance en descubierta puede estar originada en que el sustantivo francés découverte significa, además de descubrimiento, «exploration, reconnaissance du terrain en vue d'observer la présence ou l'absence d'ennemis» y la locución adverbial à la découverte «en vue d'explorer ou de reconnaître un terrain» (CNRTL, 2019. S.v. découverte).

25 En todo caso, los traductores al italiano y al inglés entendieron que voyage de découverte significaba algo diferente cuando tradujeron el término francés por «viaggio di scoperta» (Hyppolite, 1972: 7) y «voyage of discovery» (Hyppolite, 1974b: 3), respectivamente. 
cuando la proferencia se interpreta de acuerdo con su significado literal. Aunque también se pueden encontrar ejemplos del uso de frases con doble sentido en textos académicos, quizás donde se encuentren con más frecuencia sea en los textos con intenciones humorísticas. Consideremos el siguiente ejemplo en el que un legionario romano demuestra a Asterix que sabe la contraseña del día:

(13) «Je pense bien: Cogito, ergo sum» (Goscinny \& Uderzo, 1967a: 41).

(13) contiene dos alusiones distintas, una más evidente y otra un poco más discretamente disimulada. La alusión evidente consiste en la propia contraseña del legionario, que es, obviamente, la cita recortada ${ }^{26}$ que se suele hacer de la frase más conocida de la versión latina del Discurso del método, de R. Descartes. Dado que se supone que esta cita - y la alusión a su autor- son lo suficientemente conocidas, los traductores de (13) a las diversas lenguas han mantenido el texto original y no se han visto en la obligación de añadir ninguna nota explicativa, como sí se ha hecho con otros casos en los que incluso se ha censurado el texto original en aras de la corrección política (Chamizo Domínguez, 2018: 216-217).

La segunda alusión de (13) es quizás más interesante para mis propósitos, por cuanto que radica en la doble interpretación que es susceptible de recibir un modismo francés, que, por razones obvias, no puede ser mantenida en otras lenguas. Ello obliga a que las traducciones de (13) no puedan ser literales y, en el mejor de los casos, solamente puedan recoger uno de los dos significados de la frase francesa original. Efectivamente, la aseveración "Je pense bien» podría ser interpretada, prima facie, como un modismo ${ }^{27}$ cuyo significado sería equivalente a las exclamaciones castellanas ¡Desde luego!, ¡Por supuesto! o ¡Claro que sí!; que es la opción que eligió el traductor al castellano cuando vertió (13) como "Claro que sí. 'Cogito, ergo sum.'”(Goscinny \& Uderzo, 1967c: 41). Pero, además, es posible una doble lectura de (13) consistente en entenderla también como una alusión al cartesianismo como el modo correcto de pensar en el que

26 Como en otros muchos casos de frases famosas en la historia de la filosofía, la frase de Descartes se suele citar recortada. La frase original de la traducción latina del Discurso del método es «Ego cogito, ergo sum, sive existo» (Descartes, 1897b: 558).

27 " [À la forme exclam.; dans un propos rapporté au style dir., sert à renforcer ou constitue une affirm.] Tu penses! Synon. de tu parles, en effet, évidemment, bien sûr!» (CNRTL, 2019. S.v. penser). 
se relacionan la existencia y el pensamiento; que es la opción que hicieron suya los traductores de (13) al inglés, quienes lo vertieron como «I should think I am. Cogito, ergo sum». (Goscinny \& Uderzo, 1967b: 41).

$\mathrm{Y}$, además, hay una variante de los problemas que pueden surgir al traductor de una alusión y que no depende de la lengua origen ni de la lengua término del proceso de traducción, sino de convicciones culturales de los hablantes de una y de otra lengua. Este problema puede ser ilustrado con el siguiente ejemplo:

(13.1) "Jolitorax a été élevé dans la tribu des Cambridges qui sont, avant tout, d'excellents rameurs» (Goscinny \& Uderzo, 1966a: 7).

En (13), sus autores hacen una inocua, inocente y anacrónica alusión al hecho de que los estudiantes de la universidad inglesa de Cambridge suelan practicar el remo (Muñoz Calvo y Buesa Gómez, 2010: 456). Dado que (13) fue escrito pensando en un lector francés, es probable que ni tan siquiera sus autores fuesen conscientes de que la alusión a la habilidad como remero de Jolitorax, en la medida en que se le imagina como un egresado de Cambridge, pudiese levantar suspicacias en algún sitio. De hecho, las traducciones de (13) al castellano y al portugués, "Educado en la tribu de Cambridge, Buentorax es un excelente remero...» (Goscinny \& Uderzo, 1970: 7) y "Jolitorax tinha sido criado na tribo dos Cambridges que são, antes demais, excelentes remadores» Goscinny \& Uderzo, 1985: 7), respectivamente, repiten exactamente la alusión del original. Ahora bien, la alusión a la excelencia en el remo de los cantabrigenses puede ser interpretada como teniendo la implicatura de minusvaloración a sus sempiternos contrincantes en las regatas, los oxonienses. Y la posibilidad de esta interpretación no podía escapar a los traductores al inglés, quienes la evitan por medio de un término que incluye a las dos universidades: Oxford y Cambridge: «Anticlimax was brought up in the tribe of Oxbrigienses, famed for their skill in rowing» (Goscinny \& Uderzo, 1966b: 7) ${ }^{28}$. Es

28 Aunque se salga un poco del tema central que se analiza en este trabajo, no quiero dejar pasar la ocasión de señalar que, así como el texto inglés ha podido mantener la polisemia del verbo francés élever, al traducirlo por el verbo inglés bring up, el texto castellano y el texto portugués han tenido que optar por uno de los dos significados destacados del verbo francés. El resultado de ello es que, según el texto español, el personaje en cuestión ha sido educado (o ha estudiado), pero no necesariamente criado, en la tribu de Cambridge; y, por su parte, según el texto portugués, el personaje ha sido criado allí, pero no necesariamente ha estudiado allí. 
probable que se pueda mantener que el significado referencial de la alusión no varía demasiado entre el texto original francés y su traducción al inglés ya que su objetivo principal era subrayar las habilidades como remero del personaje. Pero, desde el punto de vista axiológico y cultural, es probable que lo que no es más que una inocente alusión en francés, castellano y portugués, se pueda interpretar por parte de un lector inglés como un agravio comparativo con respecto a la Universidad de Oxford, si no se introduce el cambio que introdujeron los traductores ingleses.

\section{Conclusiones.}

Aunque la alusión es un recurso lingüístico y cognitivo de primera magnitud y que se ha usado abundantemente lo mismo en el lenguaje cotidiano que en textos poéticos, políticos o filosóficos, tradicionalmente ha recibido poca atención por parte de los teóricos del lenguaje. En el mejor de los casos, la alusión se ha considerado un recurso retórico sin demasiada relevancia cognitiva. No obstante, y en la medida en que también en los textos filosóficos la alusión es un recurso cognitivo recurrente, en este trabajo se ha intentado poner de manifiesto dos cosas: 1) la relevancia de la comprensión de las alusiones para la compresión completa del texto de que se trate y del pensamiento de su autor; y 2) las características de las alusiones.

La primera ha sido poner de manifiesto cómo la comprensión de un texto filosófico viene condicionada por la previa comprensión de las alusiones que el autor del texto ha hecho, muchas de las cuales pueden ser sumamente crípticas para el lector del texto en cuestión, especialmente si se trata de textos del pasado.

Con respecto a la segunda, el análisis realizado en este trabajo apunta a las relaciones conceptuales y lingüísticas entre implicatura y alusión, lo que conlleva el que ambas compartan varias características. Las principales de estas características son:

1. El oyente tiene que poder ser (y serlo de hecho) cooperativo; de modo que, cuando el oyente no es (o no quiere serlo) cooperativo, la alusión no cumple con su función cognitiva.

2. Para que se dé la primera característica, hablante y oyente deben compartir una serie de saberes, creencias, opiniones o usos sociales. Cuando esto no ocurre, la alusión no es efectiva. Por el contrario, la comprensión 
de una alusión es muestra de una cierta intimidad entre hablante y oyente, a la vez que colabora en el acrecentamiento de esta intimidad.

3. Una alusión debe ser, por definición, ambigua o, preferentemente, vaga. Cuando una alusión pierde su ambigüedad o vaguedad, deja de ser tal y se convierte en una cita explícita.

4. Como consecuencia de las características anteriores, una alusión siempre es susceptible de cancelarse, sea por desconocimiento del oyente sea porque el oyente hace conscientemente una interpretación diferente de la que el hablante pretendía que se hiciese.

5. La función cognoscitiva - e incluso el que una proferencia dada se considere o no una alusión- depende de la lengua en que se haga.

\section{REFERENCIAS BIBLIOGRÁFICAS}

Abbagnano, N. (1971): Dizionario di filosofia. Torino: Unione Tipografico-Editrice Torinese.

Aristotele (1992): Peotica, in Opere II. Traduzione di Manara Valgimigli. Roma/Bari: Laterza.

Aristotele (2004): Retorica e Poetica. A cura di Marcello Zanatta. Torino: Unione Tipografico-Editrice Torinese.

Aristóteles (1974): Poética. Edición trilingüe de Valentín García Yebra. Gredos: Madrid.

Aristotle (1959): De Poetica, in Works, XI. Translated into English under the Editorship of W. D. Ross. Translated by Ingram Bywater. Oxford: Clarendon Press.

Audi, R. (Ed.) (1999): The Cambridge Dictionary of Philosophy. Cambridge: Cambridge University Press, $2^{\mathrm{a}}$.

Baldick, C. (2001): The Concise Oxford Dictionary of Literary Terms. Oxford: Oxford University Press.

Baldwin, J. M. (Ed.) (1901): Dictionary of Philosophy and Psychology. New York/London: Macmillan.

Benveniste, É. (1974): Problèmes de linguistique générale II. Paris: Gallimard.

Beristáin, H. (1995): Diccionario de retórica y poética. México: Porrúa.

Black, M. (1954-1955): «Metaphor». Proceedings of the Aristotelian Society, 55, pp. 273-294. 
Borchert, D. M. (Ed.) (2006): Encyclopedia of Philosophy, 10 vols. Detroit: Thomson Gale.

Brother Azarias (1904): Books and Reading. New York: The Cathedral Library Association.

Brown, K. (Ed.) (2006): Encyclopedia of Language and Linguistics. 12 Vols. Oxford: Elsevier.

Browning, R. (2007): The Poems of Robert Browning, III. 1847-1861. Edited by J. Woolford, D. Karlin and J. Phelan. Harlow: Pearson Education [c.1850].

Cervantes Saavedra, M. de (1911): El ingenioso hidalgo don Quijote de la Mancha. Edición y notas de Francisco Rodríguez Marín. 8 Vols. Madrid: Ediciones La Lectura [1605].

Chamizo Domínguez, P. J. (1988): “'Tú eres la miel de mi vida’. (Aproximación pragmática al significado de proferencias metafóricas e irónicas)», Cable, 1, pp. 23-24.

Chamizo Domínguez, P. J. (2017): «Lo que dan a entender (y también ocultan) las traducciones de los títulos de algunas obras filosóficas», Estudios Filosóficos, LXVI, pp. 39-57.

Chamizo Domínguez, P. J. (2018): «Problems translating tabooed words from source to target language», in K. Allan (Ed.), The Oxford Handbook of Taboo Words and Language, Oxford: Oxford University Press, pp. 186-205.

Chamizo Domínguez, P. J. y Rojas Jiménez, A. (2019): «El dualismo cartesiano y su relación con la nueva medicina a la luz de su correspondencia», Kriterion, 60 (143), pp. 239-256.

Chamizo-Domínguez, P. J. y Bretones-Callejas, M. ${ }^{\text {a }}$ del C. (2005): «Euphemisms, Proverbs, Allusions, and Cognition: A Study of Two Poems by Antonio Machado", Círculo de Lingüistica aplicada a la comunicación, 22. Disponible en: http://www.ucm.es/info/circulo/no22/chamizo.htm

CNRTL (2019): Centre National de Ressources Textuelles et Lexicales. Disponible en: https://www.cnrtl.fr/definition/ [Consultado el 27 de noviembre de 2019].

Cohen, T. (1978): «Metaphor and the Cultivation of Intimacy», in S. Sacks (Ed.), On Metaphor, Chicago: Chicago University Press, pp. 1-10.

Cohen, T. (1999): Jokes: Philosophical Thoughts on Joking Matters. Chicago: Chicago University Press. 
Coombs, J. H. (1984): «Allusion Defined and Explained», Poetics, 13, pp. 475-488.

Delgado Mateo, J. A. (2012): «Héroes y hechos desconocidos. Lecciones... ¿aprendida?», Minerva. Revista de la Academia General Básica de Suboficiales, 115, pp. 33-34.

Descartes, R. (1897a): Discours de la méthode pour bien conduire sa raison et chercher la vérité dans les sciences, in Euvres VI. Publiées par C. Adam \& P. Tannery. Paris: Léopold Cerf [1637].

Descartes, R. (1897b): Specimina Philosophia: seu dissertatio de methodo rectè regende rationis, \& veritatis in scientiis investigande, in CEuvres VI. Publiées par C. Adam \& P. Tannery. Paris: Léopold Cerf [1644].

Descartes, R. (2008): Discurso del método. Traducción de Eduardo Bello Reguera. Madrid: Tecnos.

DLE (2019): Diccionario de la lengua española. Real Academia de la Lengua. Disponible en: https://dle.rae.es/ [Consultado el 13 de diciembre de 2019].

Eisler, R. (1910): Wörterbuch der philosophischen Begriffe. 3 Vols. Berlin: Ernst Siegfried Mittler und Sohn.

Fernández, M. y Gaspin, F. (1991): «Astérix en español y/o la opacidad de la traducción de un código cultural», in M. ${ }^{\mathrm{a}}$ L. Donaire y F. Lafarga (Eds.). Traducción y adaptación cultural: España-Francia. Oviedo: Universidad de Oviedo, pp. 94-106.

Ferrater Mora, J. (2004): Diccionario de filosofía. 4 Vols. Nueva edición revisada aumentada y actualizada por Josep-Maria Terricabras. Barcelona: Ariel.

García Cano, M. ${ }^{a}$ I. (2017): «Caballerizas Reales. El gran proyecto de Felipe II para Córdoba», Boletín de la Real Academia de Córdoba, 166, pp. 53-82.

García Wiedemann, E. J. (1995): “'Proverbios y cantares’ de Antonio Machado no incluidos en Poesías completas», Actas del XII Congreso de la Asociación Internacional de Hispanistas, IV, pp. 165-179.

Genette, G. (1982): Palimpsestes. La littérature au second degré. Paris: Éditions du Seuil.

Gilson, É. (1987): Discours de la méthode. Texte et commentaire. Paris: Librairie Philosophique J. Vrin [1925].

Goscinny, R. \& Uderzo, A. (1964a): Astérix gladiateur. Paris: Dargaud. 
Goscinny, R. \& Uderzo, A. (1964b): Asterix the Gladiator. English translation by A. Bell \& D. Hockridge. London: Hodder Dargaud.

Goscinny, R. \& Uderzo, A. (1964c): Asterix gladiador. Traducción de Jaime Perich. Barcelona: Grijalbo.

Goscinny, R. \& Uderzo, A. (1966a): Astérix ches les Bretons. Paris: Dargaud.

Goscinny, R. \& Uderzo, A. (1966b): Asterix in Britain. English translation by A. Bell \& D. Hockridge. London: Hodder Dargaud.

Goscinny, R. \& Uderzo, A. (1967a): Astérix légionnaire. Paris: Dargaud.

Goscinny, R. \& Uderzo, A. (1967b): Asterix the Legionary. English translation by A. Bell \& D. Hockridge. London: Hodder Dargaud.

Goscinny, R. \& Uderzo, A. (1967c): Asterix legionario. Traducción de J. Perich. Barcelona: Grijalbo.

Goscinny, R. \& Uderzo, A. (1970): Asterix en Bretaña. Traducción de J. Perich. Barcelona: Bruguera.

Goscinny, R. \& Uderzo, A. (1985): Asterix entre os Bretóes. Tradução de J. F. Pontual. São Paulo: Editora Record.

Grice, P. H. (1989): Studies in the Way of the Words. Cambridge [Mass.]: Harvard University Press.

Grice, P. H. (1991): «Lógica y conversación» (Versión castellana de J. J. Acero), in L. Ml. Valdés Villanueva (Ed.), La búsqueda del significado. Madrid: Tecnos y Universidad de Murcia, pp. 511-530.

Hyppolite, J. (1941): Genèse et Structure de la Phénoménologie de l'Esprit de Hegel I. Paris: Aubier-Montaigne.

Hyppolite, J. (1972): Genesi e struttura della 'Fenomenologia dello spirito' di Hegel. Traduzione di G. A. De Toni. Firenze: La Nuova Italia.

Hyppolite, J. (1974a): Génesis y estructura de la Fenomenología del Espiritu de Hegel. Traducción de F. Fernández Buey. Barcelona: Península.

Hyppolite, J. (1974b): Genesis and Structure of Hegel's Phenomenology of Spirit. Translated by S. Cherniak and J. Heckman. Evanston: Northwestern University Press.

Irwin, W. (2001): "What is an Allusion?», Journal of Aesthetics and Art Criticism, 59 (3), pp. 288-297.

Irwin, W. (2004): «Against Intertextuality», Philosophy and Literature, 28 (2), pp. 227-242. 
Janik, A. y Toulmin, S. (1973): Wittgenstein's Vienna. New York: Simon \& Schuster.

Lalande, A. (1976): Vocabulaire technique et critique de la philosophie. Paris: Presses Universitaires de France [1926].

Lamarque, P. V. (Ed.) (1997): Concise Encyclopedia of Philosophy of Language. Oxford: Elsevier.

Locke, J. (1908): An Essay Concerning Human Understanding, in The Philosophical Works. Two Vols. Edited with a preliminary essays and notes by J. A. St. John. London: George Bell and Sons [1690].

Machacek, G. (2007): «Allusion», PMLA, 122 (2), pp. 522-536.

Machado, A. (1988): Proverbios y cantares, in Obras completas I. Edición crítica de O. Macrì. Madrid: Espasa-Calpe/Fundación Antonio Machado [1917-1924].

Marcil-Lacoste, L. (1988): «L'héritage cartésien : l'égalité épistémique», Philosophiques, 15 (1), pp. 77-94.

Martínez Alfaro, M. ${ }^{a}$ J. (1996): «Intertextuality: Origins and development of the concept», Atlantis, XVIII (1-2), pp. 268-285.

Mey, J. L. (Ed.) (2009): Concise Encyclopedia of Philosophy of Pragmatics. Oxford: Elsevier.

Montaigne, M. de (1909): Journal de Voyage. Publié avec une introduction, des notes, une table des noms propres et la traduction du texte italien par L. Lautrey. Paris: Hachette [1774].

Montaigne, M. de (2002): Les Essais. Édition établie et présentée par C. Pinganaud. Paris: Arléa [1580-1588].

Montaigne, M. de (2005): Ensayos completos. Traducción de A. Montojo. Madrid: Cátedra.

Muñoz Calvo, M. y Buesa Gómez, C. (2010): «Ils sont fous ces traducteurs!: La traducción del humor en cómics de Asterix», in R. Rabadán, T. Guzmán y M. Fernández (eds.), Lengua, traducción, recepción. En honor de Julio César Santoyol Language, Translation, Reception. To Honor Julio César Santoyo. León: Universidad de León, pp. 419-476.

Muñoz Molina, A. (1998): «El hombre titular», El país semanal, 19 de julio de 1998, p. 94.

Musolff, A. (2017): «Irony and sarcasm in follow-ups of metaphorical slogans», in A. Athanasiadou y H. L. Colston (Eds.), Irony in Language Use and Communication. Amsterdam: John Benjamins, pp. 127-141. 
Nueva Biblia Española (1975). Traducción de los textos originales dirigida por L. A. Schökel y J. Mateos. Madrid: Cristiandad.

Ortega y Gasset, J. (1983a): Ensayo de estética a manera de prólogo, in Obras completas VI. Madrid: Alianza/Revista de Occidente [1914].

Ortega y Gasset, J. (1983b): Meditaciones del Quijote, in Obras completas I. Madrid: Alianza/Revista de Occidente [1914].

Ortega y Gasset, J. (1983c): El tema de nuestro tiempo, in Obras completas III. Madrid: Alianza-Revista de Occidente [1923].

Ortega y Gasset, J. (1983d): Prólogo para alemanes, in Obras completas VIII. Madrid: Alianza/Revista de Occidente [1958].

Perri, C. (1978): «On Alluding», Poetics, 7, pp. 289-307.

Pinkard, T. (2018): «Introduction», in G. W. F. Hegel, The Phenomenology of Spirit. Translated by T. Pinkard. Cambridge: Cambridge University Press.

Quillien, P.-J. (1994): Dictionnaire politique de René Descartes. Lille: Presses Universitaires de Lille.

Russell, B. (1897): An Essay on the Foundations of Geometry, Cambridge: Cambridge University Press.

Russell, B. (1901): Essais sur les fondements de la Gémoétrie. Traduction par A. Cadenat. Paris: Gauthier-Villars, Imprimeur-Libraire.

Russell, B. (1973): Ensayo sobre los fundamentos de la geometría, in Ciencia y filosofía 1897-1919. Traducción del inglés por J. Porcel. Bilbao: Aguilar.

Sagrada Biblia (1944). Versión directa de las lenguas originales por E. Nácar Fuster y A. Colunga. Madrid: Editorial Católica.

Tanesini, A. (2007): Philosophy of Language A-Z. Edinburgh: University of Edinburgh Press.

Unamuno, M. de (1916): En torno al casticismo, in Ensayos I. Madrid: Publicaciones de la Residencia de Estudiantes.

Wittgenstein, L. (1922): Tractatus Logico-Philosophicus. Bilingual edition (German-English) by C. Kay Ogden. London: Routledge and Kegan Paul.

Wittgenstein, L. (1979): Tractatus Logico-philosophicus. Versión española de E. Tierno Galván. Madrid: Alianza [1957].

Wittgenstein, L. (2003): Tractatus logico-philosophicus. Traducción, introducción y notas de L. M. Valdés Villanueva. Madrid: Tecnos. 
Wittgenstein, L. (2009): Tractatus logico-philosophicus. Traducción de J. Muñoz Veiga e I. Reguera Pérez. Madrid: Gredos.

Wittgenstein, L. (2016): Tratado lógico-filosófico/Logisch-philosophische Abhandlung. Edición crítica de TS 204, introducción y traducción de J. Padilla Gálvez. Valencia: Tirant lo Blanc.

Woolls, D. (2006): «Plagiarism», in K. Brown (Ed.), Encyclopedia of Language and Linguistics. Vol. X. Oxford: Elsevier, pp. 621-628.

Pedro J. Chamizo Domínguez es catedrático de «Lógica y Filosofía de la Ciencia» de la Universidad de Málaga. En la actualidad imparte docencia en el grado en "Filosofía» y en el máster en "Filosofía, Ciencia y Ciudadanía», de la Universidad de Málaga, así como en el máster en "Biotecnología Avanzada», de la Universidad de Málaga y la Universidad Internacional de Andalucía.

\section{Lineas de investigación:}

- Significados no literales, con especial referencia a la metáfora, el eufemismo y el disfemismo.

-Teoría de la traducción, con especial referencia a 1) la traducción de textos filosóficos, y 2) los falsos amigos.

\section{Publicaciones recientes:}

- Partial Semantic False Friends and the Indeterminacy of Translation in Philosophical Texts», en Keith Allan (ed.), Dynamics of Language Changes. Looking Within and Across Languages. Singapore: Springer, 2020, pp. 141-154.

-«Traducción y creación de contexto», SCIO. Revista de Filosofía, 18, (2020), pp. 113-147.

-«Qué Descartes elegir?», Estudios filosóficos, LXX (2021), pp. 113-147.

-(En colaboración con Igor E. Klyukanov) «On Different Translations of Aristotle's Definition of Rhetoric: Implicatures and Implications», en Larisa Čović (Ed), Novo i traditionalno u translatologiji i navasti ruskog jezika kao stranog/ Новое и традиционное в переводоведении и преподавании русского языка как иностранного/New and Traditional in Translating and Teaching Russian as a Foreign Language. Banja Luka: Panevropski univerzitet Apeiron, 2021, pp, 130 150 .

Dirección electrónica: pjchamizo@uma.es 